\title{
Macrophage Phagocytosis of Aging Neutrophils in Inflammation \\ Programmed Cell Death in the Neutrophil Leads to its Recognition by Macrophages
}

\author{
John S. Savill,“ Andrew H. Wyllie, ${ }^{\ddagger}$ Janet E. Henson, ${ }^{\mathbf{5}}$ Mark J. Walport,“ Peter M. Henson, ${ }^{\mathbf{5}}$ and Christopher Haslett* \\ *Department of Medicine, Royal Postgraduate Medical School, Hammersmith Hospital, London W12 OHS, United Kingdom; \\ ${ }^{\ddagger}$ Department of Pathology, University Medical School, Edinburgh, Scotland; and ${ }^{\S}$ Department of Pediatrics, \\ National Jewish Center for Immunology and Respiratory Medicine, Denver, Colorado 80206
}

\begin{abstract}
Mechanisms governing the normal resolution processes of inflammation are poorly understood, yet their elucidation may lead to a greater understanding of the pathogenesis of chronic inflammation. The removal of neutrophils and their potentially histotoxic contents is one prerequisite of resolution. Engulfment by macrophages is an important disposal route, and changes in the senescent neutrophil that are associated with their recognition by macrophages are the subject of this investigation. Over $24 \mathrm{~h}$ in culture an increasing proportion of human neutrophils from peripheral blood or acutely inflamed joints underwent morphological changes characteristic of programmed cell death or apoptosis. Time-related chromatin cleavage in an internucleosomal pattern indicative of the endogenous endonuclease activation associated with programmed cell death was also demonstrated. A close correlation was observed between the increasing properties of apoptosis in neutrophils and the degree of macrophage recognition of the aging neutrophil population, and a direct relationship between these parameters was confirmed within aged neutrophil populations separated by counterflow centrifugation into fractions with varying proportions of apoptosis. Macrophages from acutely inflamed joints preferentially ingested apoptotic neutrophils and histological evidence was presented for occurrence of the process in situ. Programmed cell death is a phenomenon of widespread biological importance and has not previously been described in a cell of the myeloid line. Because it leads to recognition of intact senescent neutrophils that have not necessarily disgorged their granule contents, these processes may represent a mechanism for the removal of neutrophils during inflammation that also serves to limit the degree of tissue injury.
\end{abstract}

\section{Introduction}

The cellular events of acute inflammation are heralded by the tissue influx of large numbers of neutrophil granulocytes. These cells have a well-established potential to injure tissues by a variety of mechanisms $(1,2)$ and they have been implicated in the pathogenesis of numerous inflammatory diseases in sev-

Address correspondence to Dr. C. Haslett, Department of Medicine, Hammersmith Hospital, Du Cane Road, London W12 OHS, United Kingdom.

Received for publication 8 August 1988 and in revised form 20 October 1988.

J. Clin. Invest.

(c) The American Society for Clinical Investigation, Inc. 0021-9738/89/03/0855/11 $\$ 2.00$

Volume 83, March 1989, 865-875 eral organs (3). However, it is also clear that acute inflammation has evolved as part of a beneficial host response to injury and infection that normally resolves with minimal residual tissue damage $(4,5)$. By contrast with the initiation phase of acute inflammation, resolution is poorly understood. Therefore, the identification of mechanisms that normally govern the resolution process is likely to improve our understanding of the pathogenesis of persistent inflammation, which is a feature of many disease processes.

There are several reasons why study of the behavior of the neutrophil in inflammation is of particular interest. It is the first cell to arrive at the scene of perturbation, and subsequent or accompanying inflammatory events, such as monocyte migration and the generation of edema $(6,7)$, may depend on this initial neutrophil accumulation. Furthermore, neutrophil contents are not only histotoxic $(1,2)$ but may also enzymatically cleave matrix proteins into chemotactic fragments (8) and thus amplify the inflammatory response. In view of its potentially injurious contents and its pivotal role in the initiation and amplification of inflammation, the fate of the neutrophil during the resolution process requires definition.

The removal of neutrophils from the inflamed site is a prerequisite for resolution to occur, but the underlying mechanisms have received little attention. It is generally accepted that effete neutrophils meet their fate in situ (4) since there is little evidence that they return to the blood from the inflamed site or that lymphatics provide a major disposal route. It is often assumed that neutrophils inevitably disintegrate in the tissues (4), although this would lead to disgorgement of neutrophil contents with the potential to cause injury and amplify inflammation. Since the classical observations made by Metchnikoff at the end of the last century $(9,10)$ there has been evidence for an alternative neutrophil disposal mechanism whereby apparently intact neutrophils are engulfed by macrophages at the inflamed site. By direct microscopy of vital preparations he observed "macrophages englobing microphages (neutrophils)" in irritated tadpole tail fins. There have been numerous subsequent observations of neutrophils contained within macrophages in the tissues of animals (11-14) and man $(15,16)$. An example of particular relevance to the fate of neutrophil in inflammation and to this study is the clinical phenomenon of Reiter's cells (macrophages that have engulfed neutrophils) which have been described in the joint aspirates of patients with various forms of arthritis $(17,18)$. Furthermore, in acute experimental peritonitis induced by thioglycollate broth (13) or Corynebacterium parvum (14), the observation of massive waves of neutrophil phagocytosis by macrophages has led to the suggestion that this process may represent the major route of neutrophil disposal.

Despite these histological observations, the mechanisms leading to the recognition and uptake of neutrophils remain 


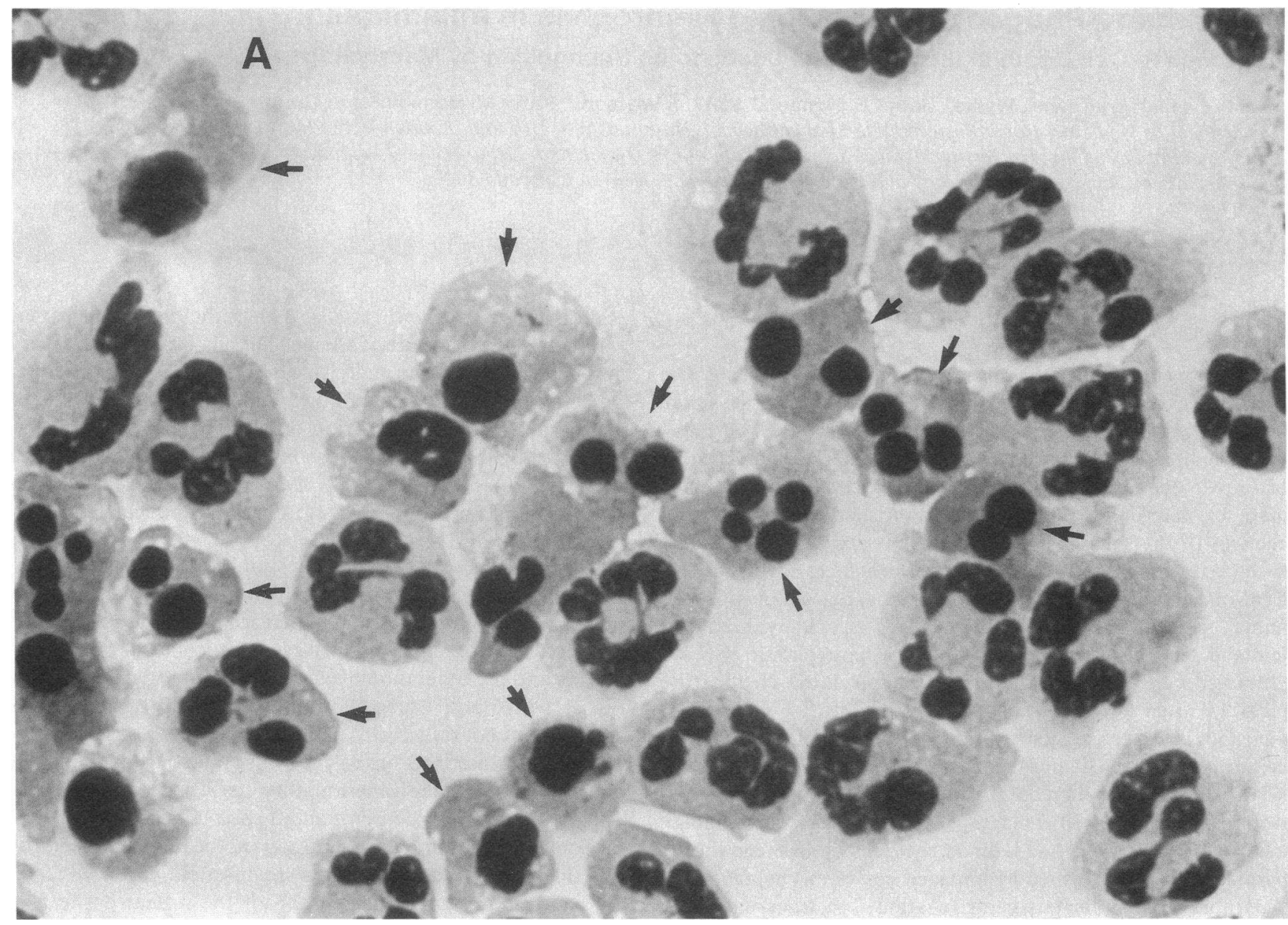

Figure 1. Morphological features of programmed cell death (apoptosis) in aging neutrophils during culture at $37^{\circ} \mathrm{C}$. $(A)$ Light microscopy of a neutrophil population aged for $10 \mathrm{~h}$. Some cells (arrows) have densely condensed nuclei and vacuolated cytoplasm $(\times 1,000)$. $(B)$ Electron microscopy of the same population, showing chromatin aggregation, nucleolar prominence (arrow), and cytoplasm vacuolation, while the granules remain intact $(\times 12,000)$. (C) Time course of appearance of neutrophils with the morphological features of apoptosis after isolation from blood of five normal donors $(\bullet)$. There was minimal loss of cells ( $\Delta$, as \% of starting number) or viability ( $0, \%$ population excluding trypan blue) and little spontaneous release of MPO into the medium during $24 \mathrm{~h}(\diamond)$, expressed as a percent of total.

obscure. We have previously reported that macrophages derived from acutely inflamed sites or matured from monocytes in vitro were capable of ingesting neutrophils that have been aged in vitro (19), but the changes in the aging neutrophils that were responsible for recognition by macrophages as senescent self were not identified.

It is shown here that with time increasing numbers of neutrophils undergo characteristic morphological changes and a chromatin fragmentation pattern indicative of programmed cell death or apoptosis. This process leads to the recognition by macrophages of senescent but otherwise intact neutrophils and may represent an injury-limiting neutrophil disposal mechanism important in the normal resolution of inflammation. Human neutrophils isolated from acutely inflamed joints undergo this process and macrophages from these joints also preferentially recognize joint-derived neutrophils that have undergone programmed cell death. Evidence is presented that the Reiter's cell of acute inflammatory arthritides represents a histological manifestation of these processes in situ.

\section{Methods}

Materials. All chemicals used were from Sigma Chemical Co., St. Louis, MO, unless otherwise indicated. Percoll was obtained from Pharmacia Fine Chemicals, Piscataway, NJ, citrate from Pharma Hameln GmbH., Hanover, W. Germany, culture media (HBSS, Iscove's DME) and supplements (100 U/liter of penicillin and streptomycin) from Gibco Laboratories, Grand Island, NY, Tropolone (2-hydroxy2,4,6-cycloheptatrienone) from Fluka AG, Buchs, Switzerland, and sterile tissue culture plasticware from Falcon Plastics, Cockeysville, MD.

Cell isolation and culture. Granulocytes (PMN, $>98 \%$ pure on May-Giemsa stained cytopreps) were isolated from the peripheral blood of healthy volunteers by a combination of dextran sedimentation and centrifugation through discontinous plasma-Percoll gradients as described (20). This technique was designed to minimize exposure of the cells to bacterial endotoxin and thus preserve them in a minimally activated state; it was found that standard preparative techniques such as the use of Ficoll-Hypaque (Pharmacia Fine Chemicals) with erythrocyte lysis resulted in neutrophil activation and significant loss of cells during aging by clumping and loss of membrane integrity (20, and unpublished data). Thus, in brief, PMN were prepared as 

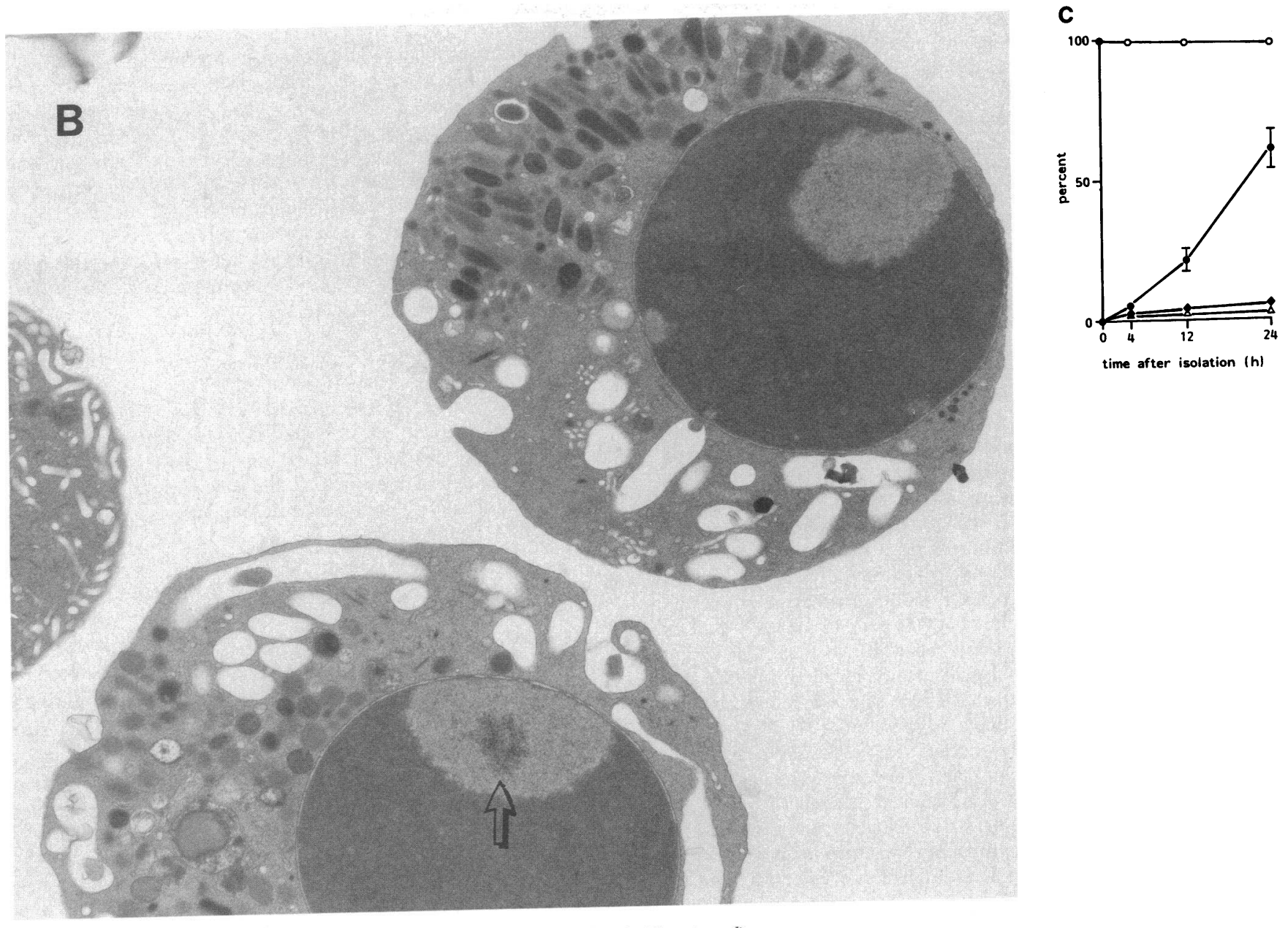

Figure 1. (Continued)

follows: freshly drawn venous blood was citrated $(4.4 \mathrm{ml}$ of $3.8 \%$ sodium citrate to $40 \mathrm{ml}$ blood) in $50-\mathrm{ml}$ polyethylene tubes (Falcon Plastics), centrifuged at $300 \mathrm{~g}$ for $20 \mathrm{~min}$ at $20^{\circ} \mathrm{C}$, and the platelet-rich plasma aspirated and centrifuged at $2,500 \mathrm{~g}$ for $10 \mathrm{~min}$ for production of platelet-poor plasma (PPP) ${ }^{1}$ or recalcified $(20 \mathrm{mM}$ final concentration calcium chloride added) to prepare platelet-rich, plasma-derived serum (PRPDS). To the red and white cells remaining in each tube, 5 $\mathrm{ml}$ of $6 \%$ dextran $(500,000 \mathrm{~mol} \mathrm{wt})$ in $0.9 \%$ saline was added, and the contents made up to $50 \mathrm{ml}$ with $0.9 \%$ saline, mixed gently, and then allowed to stand for erythrocyte sedimentation for $30 \mathrm{~min}$. The leukocyte-rich plasma was aspirated, centrifuged at $275 \mathrm{~g}$ for $6 \mathrm{~min}$, resuspended in $2 \mathrm{ml} \mathrm{PPP}$, and transferred to a $15-\mathrm{ml}$ polystyrene tube. The leukocyte suspension was then underlayered with $2 \mathrm{ml}$ of $42 \%$ stock Percoll (9:1 vol/vol Percoll-0.9\% saline) in PPP, followed by $2 \mathrm{ml} 51 \%$ stock Percoll in PPP. The gradients were centrifuged at $275 \mathrm{~g}$ for 10 $\mathrm{min}$ and PMN were then aspirated from the interface of the 51 and $42 \%$ steps. After three washes PMN were suspended at $5 \times 10^{6} / \mathrm{ml}$ in Iscove's DME with $10 \%$ autologous PRPDS and $100 \mathrm{U} /$ liter of penicillin and streptomycin and then incubated at $37^{\circ} \mathrm{C}$ in a $5 \% \mathrm{CO}_{2}$ atmosphere for up to $24 \mathrm{~h}$. At the time points described in the text cells were counted on a hemocytometer and their viability assessed by trypan blue exclusion. Cytocentrifuge preparations were fixed in methanol, stained with May-Giemsa, and examined by oil-immersion light microscopy. For assessment of the percentage of cells showing mor-

1. Abbreviations used in this paper: $\mathbf{M} \phi$, monocyte-derived macrophages; MPO, myeloperoxidase; PPP, platelet-poor plasma; PRPDS, platelet-rich plasma-derived serum. phology of apoptosis (see Results) 1,000 cells/slide were examined. Cells were also fixed in $1 \%$ glutaraldehyde in $0.1 \mathrm{M}$ cacodylate buffer, $\mathrm{pH} 7.3$, postfixed in $1 \%$ osmium tetroxide and $0.1 \mathrm{M}$ cacodylate buffer, and processed for ultrastructural analysis by routine electron microscopical techniques. Myeloperoxidase (MPO) spontaneously released into the culture medium was assayed by routine methods (21) after the cells had been pelleted at $275 \mathrm{~g}$ for $6 \mathrm{~min}$.

Inflammatory PMN were isolated from synovial fluid freshly aspirated from the joints of patients presenting with acute sterile arthritis (in most cases due to seropositive or seronegative rheumatoid disease, but three patients had osteoarthritis and one Behçet's disease; none had evidence of antineutrophil antibodies). Viability counts and cytocentrifuge preparations were done with synovial fluid diluted with PBS within $10 \mathrm{~min}$ of fluid aspiration and May-Giemsa stained slides were examined for neutrophil apoptosis and macrophage phagocytosis of neutrophils. For aging studies, synovial inflammatory cells were washed three times in PBS and then PMN purified and aged by methods identical to those above, except that dextran sedimentation was only used in those experiments in which a direct comparison was made with PMN isolated from the patient's blood, and 38/50\% stock Percoll in PPP density gradients was found to be necessary for cell purification, reflecting the known changes in density in neutrophils after activation (22). Samples from some patients had to be discarded during preparation because of irreversible PMN clumping, but it was found that this problem could be largely overcome either by using washes in cold $\left(4^{\circ} \mathrm{C}\right)$ PBS before preparation, or adding $2 \mathrm{ml}$ citrate to $50 \mathrm{ml}$ synovial fluid on aspiration. Similar results were obtained with both methods. 
Monocyte-derived macrophages $(\mathrm{M} \phi)$ were prepared from donated blood by routine methods (23). Briefly, mixed mononuclear cells from the density gradients were washed three times, suspended in Iscove's DME at $4 \times 10^{6} / \mathrm{ml}$, and $1 \mathrm{ml}$ added to each well of 24-well tissue culture plates. After $1 \mathrm{~h}$ incubation at $37^{\circ} \mathrm{C}$ and $5 \% \mathrm{CO}_{2}$ the wells were washed and adherent monocytes cultured for $7 \mathrm{~d}$ in Iscove's DME with $10 \%$ autologous PRPDS, the medium being changed at $3 \mathrm{~d}$.

Separation of aged PMN populations into fractions with varying proportions of apoptosis was achieved by counterflow centrifugation using a centrifuge (J-2 21; Beckman Instruments, Inc., Palo Alto, CA) and elutriation rotor at 2,500 rpm. Aged PMN were washed and loaded into the elutriation chamber at $30 \times 10^{6} / \mathrm{ml}$ in HBSS with an elutriation flow rate of $14 \mathrm{ml} / \mathrm{min}$. At flow rates between 28 and 48 $\mathrm{ml} / \mathrm{min}$ cells obtained in $100-\mathrm{ml}$ elutriation fractions were assessed for trypan blue exclusion and percentage apoptosis and adjusted to 5 $\times 10^{6} / \mathrm{ml}$ for interaction with $\mathbf{M} \phi$.

Chromatin fragmentation assays. Assessment of chromatin fragmentation in aging neutrophils was by a modification of methods previously described for thymocytes $(24,25)$. Neutrophils were lysed by mixing $0.5 \mathrm{ml}$ of cell suspension $\left(1 \times 10^{8} / \mathrm{ml}\right)$ with $4.5 \mathrm{ml}$ lysis buffer (Tris, pH 8.0, $20 \mathrm{mM}$ EDTA, 2\% Triton X-100). After standing for $1 \mathrm{~h}$ at $4^{\circ} \mathrm{C}$ the lysate was centrifuged at $25,000 \mathrm{~g}$ for $2 \mathrm{~min}$ at $4^{\circ} \mathrm{C}$ to separate high from low molecular weight chromatin. DNA for quantitative measurement was precipitated from the supernatant by addition of TCA to $5 \%$ and centrifugation at $1,000 \mathrm{~g}$ for $15 \mathrm{~min}$ at $4^{\circ} \mathrm{C}$. This TCA precipitate and the previously pelleted high molecular weight chromatin were then hydrolyzed by incubation for $15 \mathrm{~min}$ at $95^{\circ} \mathrm{C}$ in 2 $\mathrm{ml}$ TCA, and the released deoxynucleotide sugars were measured by the diphenylamine reaction as previously described $(24,25)$. Duplicate or triplicate lysates were made from each sample. The DNA in the low molecular weight fraction of chromatin was expressed as a percentage of the total recovered DNA (which remained stable at 12 and $24 \mathrm{~h}$ at $>80 \%$ of the initial sample in the six experiments shown in Fig. $2 \mathrm{~A}$ ). DNA for analysis by gel electrophoresis was precipitated from the $25,000 \mathrm{~g}$ supernatant after lysis by addition of $2 \mathrm{vol}$ ethanol and $0.1 \mathrm{vol}$ $5 \mathrm{M} \mathrm{NaCl}$ at $20^{\circ} \mathrm{C}$ overnight. The precipitate, collected by centrifugation at $10,000 \mathrm{~g}$ for $15 \mathrm{~min}$ at $4^{\circ} \mathrm{C}$, was dried and resuspended in $1 \mathrm{ml}$ $10 \mathrm{mM}$ Tris, pH 8.0, $1 \mathrm{mM}$ EDTA, and $1 \%$ SDS. The 25,000-g pellet from the same lysate was resuspended in the same way. After deproteinization by serial extraction as before in ethanol and $\mathrm{NaCl}$, samples were digested for $15 \mathrm{~min}$ at $37^{\circ} \mathrm{C}$ with RNAase A $(100 \mu \mathrm{g} / \mathrm{ml}$, heat treated to inactivate contaminant deoxyribonuclease), electrophoresed in a $1.0 \%$ agarose gel containing $30 \mu \mathrm{g} / \mathrm{ml}$ ethidium bromide, and viewed under ultraviolet light. A Taq I digest of pBR 322 was used as a size marker.

Macrophage-aged PMN interaction assay. Recognition of aged PMN by M $\phi$ matured from monocytes over $7 \mathrm{~d}$, as above; was assayed by minor modifications of previously described methods (19). Aged PMN were washed in HBSS and suspended at $5 \times 10^{6} / \mathrm{ml}$ in HBSS, and $1 \mathrm{ml}$ of suspension was added to each well of $\mathrm{M} \phi$ (which had been washed in $\mathrm{HBSS}$ ). After $30 \mathrm{~min}$ incubation at $37^{\circ} \mathrm{C}$ in a $5 \% \mathrm{CO}_{2}$ atmosphere, during which the PMN rapidly settled into a carpet in close association with the $\mathbf{M} \phi$ monolayer, the wells were vigorously washed with cold $\left(4^{\circ} \mathrm{C}\right) 0.9 \%$ saline, fixed with $2 \%$ glutaraldehyde in PBS, and then stained for MPO using hydrogen peroxide and dimethoxybenzidine (o-diansidine; Sigma Chemical Co.) as substrate. Aged PMN were $100 \%$ MPO-positive, while 7-d M $\phi$ were $100 \%$ MPO-negative. Interaction was quantitated by microscopic counting of the proportion of $\mathbf{M} \phi$ ingesting MPO-positive neutrophils in five randomly selected fields, at least $500 \mathrm{M} \phi$ being assessed per well. Previous studies have shown that this method gives excellent concordance with total uptake of radiolabeled PMN and that the phagocytic nature of the interaction could be confirmed by electron microscopy (19).

One patient with seropositive rheumatoid disease presented with bilateral acute arthritis of the knees. Synovial fluid was aspirated from one knee, neutrophils were isolated and radiolabeled for $5 \mathrm{~min}$ in PPP with ${ }^{111}$ In-tropolonate at a final concentration of $4 \mathrm{mM}$ (26), washed three times, and then aged for $24 \mathrm{~h}$ in standard fashion. The second knee was aspirated $21 \mathrm{~h}$ after the first, and mixed mononuclear cells from the density gradient ( $>80 \%$ pure on cytopreps) were washed and suspended at $10^{6} / \mathrm{ml}$ in Iscove's DME and then adhered to tissue culture plates at $37^{\circ} \mathrm{C}$ and $5 \% \mathrm{CO}_{2}$ for $1 \mathrm{~h}$ before vigorous washing and interaction with radiolabeled aged PMN at $5 \times 10^{6} / \mathrm{ml}$ from the first knee, which had been separated by elutriation into fractions with varying degrees of apoptosis. Uptake of radiolabeled PMN was assessed after washing of the monolayers by removing the contents of each well using cotton wool pledgelets, which were then counted in a gamma counter. Uptake (the mean of triplicate wells) was calculated as a percentage of total cell-associated radioactivity loaded into each well. $\mathrm{PMN}$ were loaded into each well at a ratio of $\sim 25 \mathrm{PMN} /$ adherent $\mathrm{M} \phi$ in order to ensure a dense, even carpet of PMN although denying many PMN the chance to interact since cells in the upper layers of the carpet would not have been directly opposed to $\mathbf{M} \phi$. Therefore, retention of $4 \%$ of loaded radioactivity indicated an average uptake of $\sim 1$ $\mathrm{PMN} / \mathbf{M} \phi$ in the 30 -min assay. However, because inflammatory $\mathbf{M} \phi$ prepared from the second knee showed some $(<20 \%)$ polymorph contamination, the data is presented as the percentage of loaded PMN ingested per well, without making the assumptions necessary to calculate mean PMN uptake per $\mathbf{M} \phi$.

\section{Results}

Aging neutrophils exhibit morphological features of apoptosis. Marked, time-related morphological changes were observed in PMN that had been isolated from blood or from inflamed joints and then aged in tissue culture (see Methods) for up to $24 \mathrm{~h}$ with negligible loss of cells. On light microscopy of aging PMN, nuclear pyknosis or chromatin condensation was seen (Fig. $1 A$ ) together with cytoplasmic vacuolation, features that suggested that aging PMN undergo programmed cell death or apoptosis (27). Ultrastructural examination (Fig. $1 B$ ) demonstrated chromatin aggregation, nucleolar prominence, and cytoplasmic vacuolation, a triad of features that are highly characteristic of apoptosis (27), and are not seen in mature, circulating PMN. The cell membrane and organelles, including granules, appeared to remain structurally intact in such cells, as in other apoptotic cells (27). Further evidence of retention of membrane integrity was obtained in time-course studies of aging PMN. The proportion of cells demonstrating morphological features of apoptosis increased progressively with time, yet $>98 \%$ of cells excluded trypan blue dye at $24 \mathrm{~h}$, and there was little spontaneous release of the granule enzyme myeloperoxidase (Fig. 1C). After $24 \mathrm{~h}$ there was a steady increase in cells that failed to exclude trypan blue and that showed signs of ballooning and ultimate disintegration.

Chromatin fragmentation in aging neutrophils. In direct relationship to stereotyped morphological changes, cells undergoing programmed cell death exhibited chromatin fragmentation in a characteristic internucleosomal pattern thought to represent endogenous endonuclease activation, the amount of DNA in each fragment being a multiple of $\sim 180$ bp $(24,25,28-31)$. In view of the morphological changes seen in aging PMN, evidence of chromatin fragmentation was sought in PMN isolated from blood and aged in the standard fashion. There was a progressive increase during aging in the proportion of PMN chromatin of molecular weight sufficiently low to resist sedimentation at $25,000 \mathrm{~g}$ and therefore presumed to represent cleaved chromatin (Fig. $2 A$ ). Furthermore, electrophoresis of DNA from the unsedimented low molecular weight chromatin of PMN aged for $24 \mathrm{~h}$ revealed the ladder with 180-bp steps typical of endonuclease activation and programmed cell death (Fig. $2 B$ ). Indeed, this pattern of 


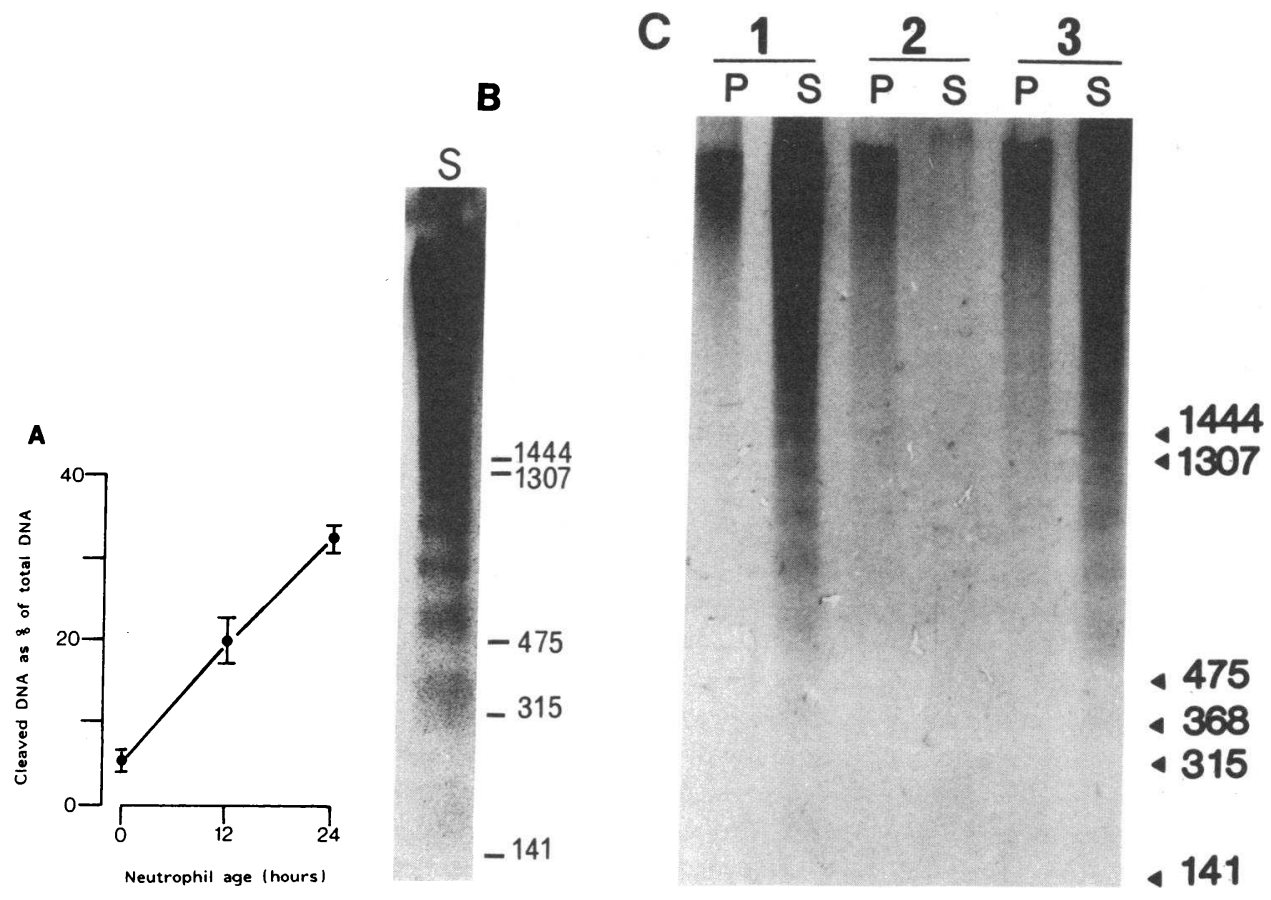

Figure 2. DNA fragmentation in aging neutrophils. $(A)$ Time-related increase in low molecular weight chromatin, which resisted centrifugation at $25,000 \mathrm{~g}$, presented as cleaved DNA as a percentage of total DNA in aging neutrophils from six normal donors. $(B)$ Electrophoresis in $1 \%$ agarose of DNA extracted from one such supernatant, viewed by ultraviolet fluorescence after ethidium bromide staining. There was a ladder pattern of low molecular weight DNA, consisting of integer multiples of $180 \mathrm{bp}$, indicative of internucleosomal cleavage. $(C)$ Electrophoresis of DNA extracted from $25,000-g$ pellets $(P)$ and supernatant $(S)$ of $25 \times 10^{6}$ lysed cells from (sample 1) a population of 24-h aged neutrophils isolated from inflammatory synovial fluid, with $56 \%$ apoptotic cells, a subpopulation with $3.2 \%$ apoptosis (sample 2) prepared by elutriation, and an elutriation fraction (sample 3) with $82 \%$ apoptosis. In samples 1 and 3 the majority of the chromatin did not sedi-

ment at $25,000 \mathrm{~g}$, and the ladder pattern was seen in the supernatant samples, while in sample 2 the majority of the DNA loaded appeared only as a high molecular weight smear. The apparently lower aggregate loading in this sample reflected preferential loss of uncleaved high molecular weight genomic DNA during extraction.

DNA cleavage was also observed in PMN isolated from an inflamed joint and aged in standard fashion (Fig. $2 C$ ), and in a subpopulation with a high $(82 \%)$ proportion of apoptotic cells prepared from this population by counterflow centrifugation, but not in a subpopulation with a low (3.2\%) proportion of apoptotic cells. Thus, aging PMN demonstrate the closely related morphological and biochemical changes of programmed cell death.

Macrophage recognition of apoptotic neutrophils from normal subjects. In cell types other than the PMN, programmed cell death leads to recognition of the cell by phagocytes (27, 32). In time-course studies it was found that $\mathbf{M} \phi$ recognition of aging PMN populations derived from the blood of normal donors progressively increased, and there appeared to be a close temporal relationship with the increasing proportion of PMN with apoptotic morphology (Fig. $3 A$ ). Indeed, when recognition and apoptosis were correlated for a large number of paired observations made with PMN at different stages of aging in culture, a highly significant relationship was found ( $r$ $=0.83, P<0.001, n=59$; Fig. $3 B$ ), suggesting that apoptosis in the aging PMN was directly linked to recognition by $\mathbf{M} \phi$. In the current study, and as we have described previously (19), the processes of macrophage recognition, ingestion, and degradation of aged neutrophils appeared to occur extremely rapidly: a phagocytic signal was present after interactions as short as $10 \mathrm{~min}$, a time at which most PMN had not settled, and degradation was so rapid that in interactions of $1 \mathrm{~h}$ and over most ingested MPO-positive material had already been reduced to small fragments. In the 30 -min interactions used here, although most ingested MPO-positive material appeared to be discrete PMN, on light and electron microscopy (19) partial degradation had already rendered it impossible reliably to assess ingested PMN for morphological features of apoptosis. To test the relationship between apoptosis and engulfment further, it was therefore necessary to compare $\mathrm{M} \phi$ recognition of subpopulations of aged PMN with high and low pro-
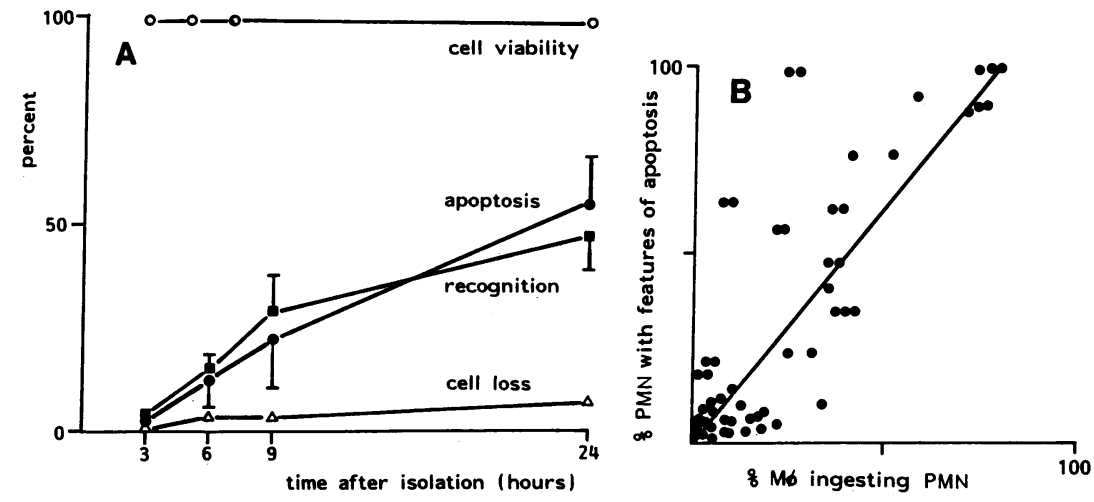

Figure 3. Temporal relationship between apoptosis and macrophage recognition of aging neutrophil populations from six normal donors. $(A)$ Approximately parallel increases in the percentage of PMN exhibiting light microscopical features of apoptosis $(\bullet)$ and the percentage of monocyte-derived $\mathrm{M} \phi$ ingesting PMN ( () at each time point. $(B)$ The significant relationship between these parameters $(r=0.83, P<0.001)$ in 59 observations made in these experiments (duplicate or triplicate interactions at each time point). Note minimal cell loss ( $\Delta$, as \% of starting total) and viability $>98 \%$ (O, by trypan blue exclusion) seen in $(A)$. 

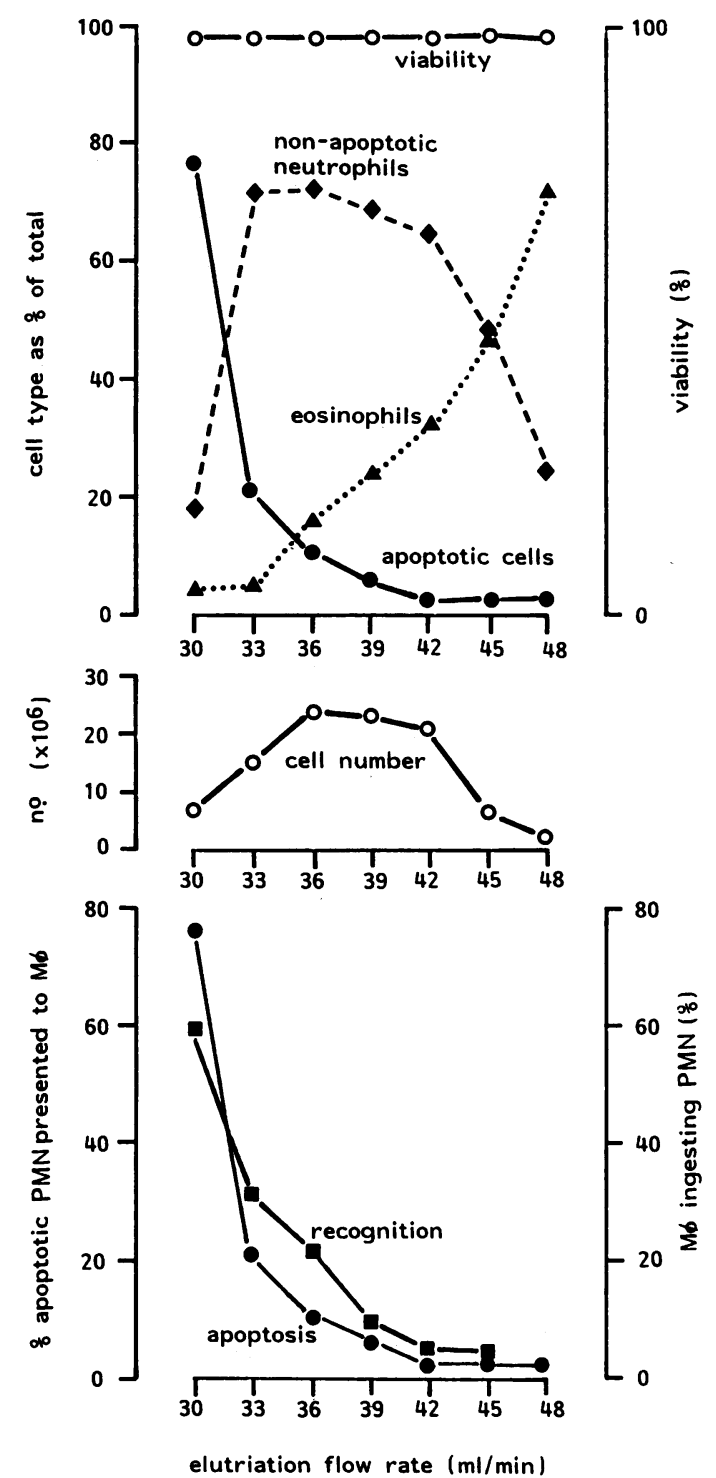

Figure 4. Separation of an aged neutrophil (PMN) population by elutriation; $M \phi$ recognition of the apoptotic subpopulation. Granulocytes were isolated from an atopic, but otherwise normal, volunteer and aged for $24 \mathrm{~h}$, after which 19\% of PMN showed light microscopical features of apoptosis, $16 \%$ were eosinophils, and the remainder appeared to be normal neutrophils. After loading into an elutriating centrifuge (see Methods), 75\% of the population was recovered between elutriation flow rates of 30 and $48 \mathrm{ml} / \mathrm{min}$, fractions being collected at $3 \mathrm{ml} / \mathrm{min}$ steps as shown; the cell numbers in each fraction are shown (middle). (top) The percentage of each cell type in MayGiemsa stained cytopreps of each fraction is shown (๑, apoptotic neutrophils; ४, nonapoptotic or normal neutrophils; and $\Delta$, eosinophils) together with \% viability by trypan blue dye exclusion (0). Aliquots of each fraction were interacted with monocyte-derived $\mathbf{M} \phi$ (see Methods) and the percentage of M $\phi$ ingesting aged PMN ( $(\square)$ can be seen to be closely related to the percentage of apoptotic neutrophils in the granulocytes presented to each $\mathrm{M} \phi$ well (interaction results are means of duplicate or triplicate wells where sufficient PMN).

portions of apoptosis, separated from single aged PMN populations. By the use of counterflow centrifugation (elutriation), aged PMN could be separated into fractions containing proportions of apoptotic neutrophils varying from 5-90\% without disrupting the cells, which retained the ability to exclude trypan blue (Fig. 4). A representative experiment (Fig. 4) demonstrates that macrophage recognition was indeed directly related to apoptosis in the aged neutrophil subpopulations. This close relationship was confirmed in a large number of observations made with fractions from different aged PMN populations, in which a highly significant correlation between recognition and neutrophil apoptosis $(r=0.81, P<0.001, n$ $=43$; Fig. 5) was obtained. Counterflow centrifugation was also helpful in confirming that the small proportion of eosinophils usually present in the PMN preparation did not contribute to the recognition signal (Fig. 4; this example is chosen since this atopic individual had $16 \%$ eosinophilia).

Macrophage recognition of apoptotic neutrophils from patients with inflammatory joint disease. Although the development of apoptosis in aging PMN derived from healthy donor blood was directly linked to recognition by $\mathrm{M} \phi$, it was felt important to determine whether PMN from inflamed sites underwent apoptosis and became recognized by $\mathbf{M} \phi$. In five patients with acute sterile arthritis (two rheumatoid arthritis, two osteoarthritis, one Behçet's disease) PMN were simultaneously purified from blood and inflammatory joint fluid by the same techniques (see Methods). When these PMN were aged for up to $22 \mathrm{~h}$ in the standard fashion there was negligible cell loss and cells retained the ability to exclude trypan blue ( $>98 \%$ at all time points, except at $22 \mathrm{~h}$ for joint PMN where the mean trypan blue exclusion of $96 \%$ included one observation of $16 \%$ trypan blue-positive cells). During this period there was a progressive increase in the proportion of cells with features of apoptosis, which occurred at comparable rates in neutrophils derived from both blood and from joint fluid (Fig. $6 \mathrm{~A}$ ). An approximately parallel increase in the degree of macrophage recognition of the aging cell populations was observed (Fig. 6 B). Separation of aged joint-derived neutrophil populations by elutriation into subpopulations with differing proportions of apoptotic cells demonstrated a close relationship between neutrophil apoptosis and recognition by $\mathrm{M} \phi$ (Fig. $6 C$ ) similar to that demonstrated for neutrophils from healthy donor blood (Fig. 5). Thus, the apoptotic subpopulation of aged joint-derived inflammatory neutrophils was responsible for recognition by monocyte-derived $\mathbf{M} \phi$ prepared from the blood of healthy donors.

A patient with acute sterile arthritis of both knees provided a unique opportunity to compare the recognition of freshly isolated and cultured aged inflammatory neutrophils by mature monocyte-derived macrophages with recognition by inflammatory macrophages isolated from the joint fluid of the

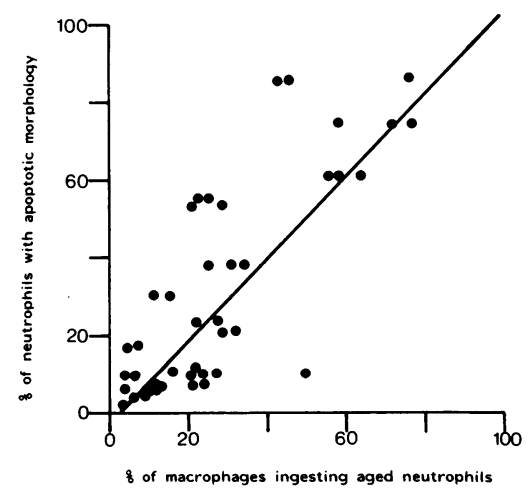

Figure 5. Correlation between apoptosis and M $\phi$ recognition of subpopulations of 24-h aged neutrophils, prepared by elutriation; 43 observations were made with cells from 5 normal donors $(r=0.81, P$ $<0.001)$. 

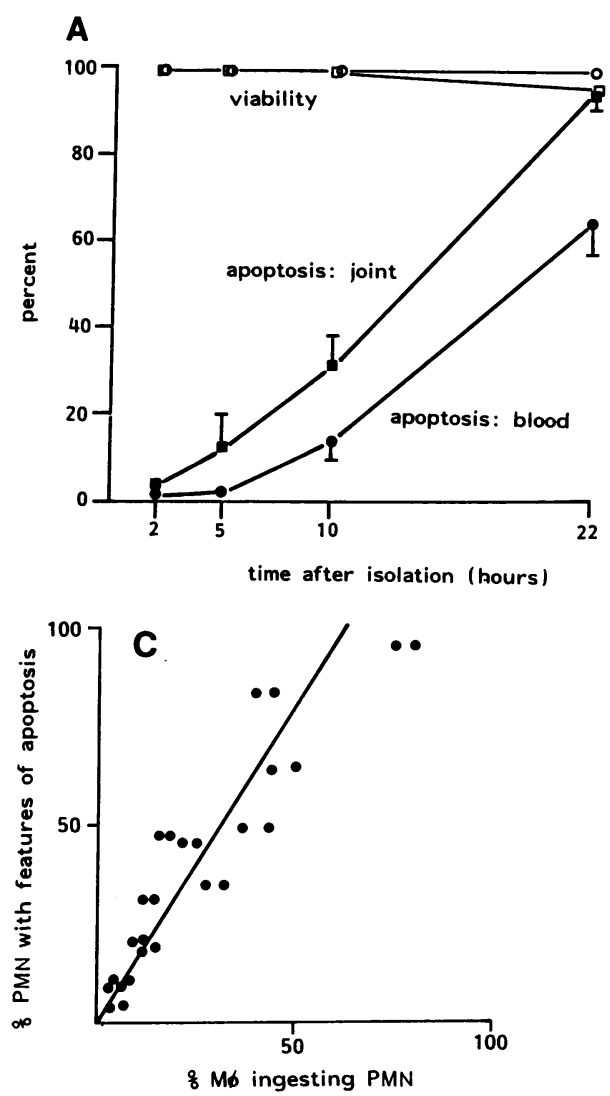

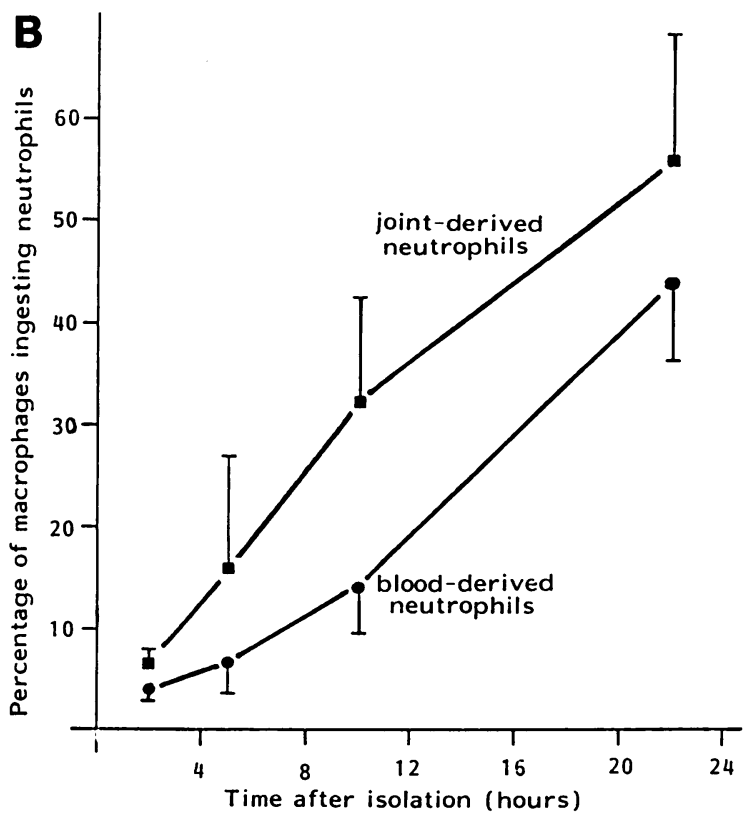

Figure 6. Programmed cell death and $M \phi$ recognition of aging neutrophils isolated from inflammatory synovial fluid. $(A)$ In five patients with acute sterile arthritis PMN were simultaneously isolated from blood and synovial fluid. During aging in vitro there was minimal loss of viability ( $\square$, joint PMN; $O$ blood PMN) but similar time-related increases in apoptosis ( $\square$, joint PMN; $\bullet$, blood PMN) and $(B)$ in recognition by monocyte-derived $\mathbf{M} \phi$. Aged synovial PMN from three donors were separated by elutriation and $(C)$ show the correlation between apoptosis and recog nition in the subpopulations prepared $(r=0.91, P$ $<0.001, n=26$ ). patient $1 \mathrm{~h}$ before interaction. Neutrophils were purified from the joint fluid aspirated from one knee, radiolabeled, and aged in the standard fashion. Joint fluid was aspirated from the second knee $21 \mathrm{~h}$ later and neutrophils and macrophages were purified as described in Methods. Aged neutrophils were fractionated into subpopulations containing varying proportions of apoptotic cells and thus fresh and aged neutrophils were interacted with both mature heterologous monocyte-derived macrophages (Fig. $7 A$ ) and freshly isolated joint-derived inflammatory macrophages (Fig. 7 B). Neutrophil recognition by joint-derived macrophages could be assessed only by uptake of radiolabeled cells since the freshly isolated macrophage population contained many MPO-positive cells (presumably immature macrophages that had not yet lost their MPO and cells that had ingested neutrophils in vivo) rendering it difficult to use the standard microscopic assay of MPO-stained monolayers (Fig. 7 B). However, neutrophil uptake by mature monocyte-derived macrophages could be assessed both by MPO staining of monolayers and by the uptake of radiolabeled neutrophils (Fig. $7 \mathrm{~A}$ ). The excellent concordance between the two methods confirms the close relationship between these two assays of neutrophil recognition as previously reported (19). It can be seen that joint-derived inflammatory macrophages and mature monocyte-derived macrophages preferentially recognized apoptotic neutrophils (Fig. 7). Because there was some granulocyte contamination $(<20 \%)$ of the freshly isolated joint-derived macrophages, it was considered important as a control to interact aged apoptotic neutrophils with a monolayer of pure freshly isolated inflammatory granulocytes (Fig. $7 \mathrm{~B}$ ). This resulted in a degree of background interaction that was no more than that observed with macrophages that had interacted with fresh joint neutrophils, thus demonstrating that the macrophages were responsible for the uptake of with apoptotic neutrophils. However, this contamination of the monolayer, by diluting available $\mathbf{M} \phi$, is one factor contributing to the apparently smaller degree of recognition of the aged PMN elutriation fractions with the highest percentages of apoptosis by inflammatory $\mathbf{M} \phi$ when compared with monocyte-derived $\mathbf{M} \phi$. Further factors contributing to this small discrepancy are, first, that many inflammatory $\mathrm{M} \phi$ show cytological features consistent with very recent PMN ingestion (see below and Fig. 8) and may therefore have a reduced capacity for PMN ingestion and second, that some adherent inflammatory monocytic cells may not have achieved the full maturity required for aged PMN ingestion (19). Nevertheless, the relationship between $\mathrm{M} \phi$ recognition and $\mathrm{PMN}$ apoptosis demonstrated with monocyte-derived $\mathrm{M} \phi$ (Fig. $7 A$ ) still held for inflammatory $\mathbf{M} \phi$ (Fig. $7 \mathrm{~B}$ ).

Cytological evidence of neutrophil apoptosis and phagocytosis by macrophages in inflammatory joint fluid. In rapidly fixed and stained (see Methods) preparations of freshly isolated joint fluid it was possible to find neutrophils with apoptotic morphology (Fig. 8), the proportion varying from $<1 \%$ to $11 \%$. This suggested that apoptosis did indeed occur in neutrophils at inflamed sites in vivo. Furthermore, in confirmation of other reports $(17,18)$ it was possible to demonstrate inflammatory $\mathbf{M} \phi$ that appeared to have ingested intact neutrophils (Fig. 8). Ingested neutrophils appeared to have condensed nuclei in those cases where the neutrophil material had not yet been markedly degraded. These cytological appearances are identical to those described in previous investigations $(17,18)$ as Reiter's cells in a variety of acute inflammatory arthritides. 
A

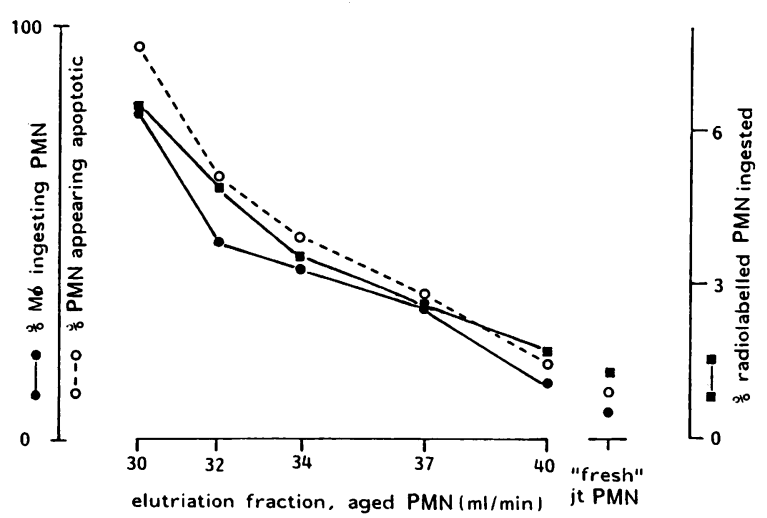

B

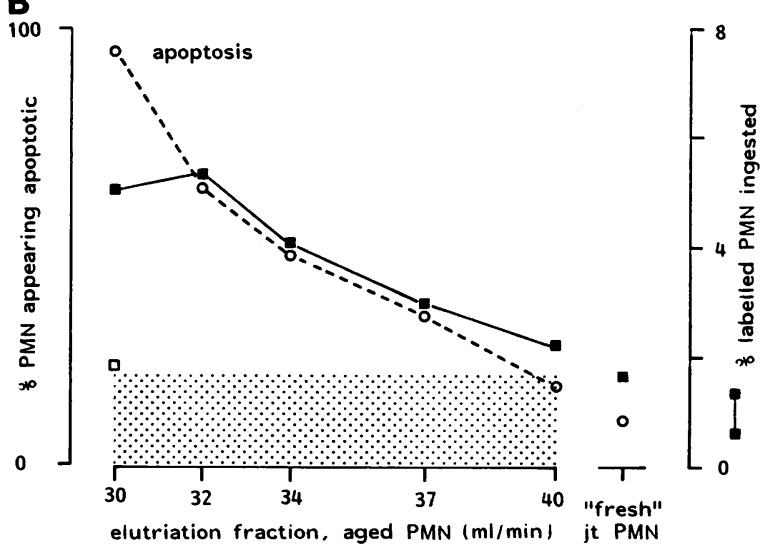

Figure 7. Macrophages freshly isolated from inflammatory synovial fluid recognize autologous apoptotic neutrophils. PMN were isolated from the left knee of a patient with bilateral acute arthritis, radiolabeled with ${ }^{111}$ In, aged in vitro, separated by elutriation into subpopulations with varying percentages of apoptotic cells, and then interacted with $(A)$ heterologous monocyte-derived $\mathbf{M} \phi$. Note the close relationship between apoptosis $(0)$ and retention of radiolabel in the well ( $\square$ ). In (B) the same fractions were interacted with freshly isolated inflammatory $\mathbf{M} \phi$. Again uptake by $\mathbf{M} \phi(\square)$ was related to apoptosis (O). The shaded area corresponds to the degree of retention of freshly isolated joint PMN (from the right knee) by the M $\phi$ monolayer. Interaction of apoptotic cells with contaminating granulocytes did not appear to account for the recognition signal since the degree of interaction with an inflammatory PMN monolayer ( $\square$ ) did not differ from that for freshly isolated PMN interacting with inflammatory $\mathbf{M} \phi$.

\section{Discussion}

In this study we show that aging neutrophils undergo programmed cell death, a process leading to their recognition as intact cells by macrophages. Programmed cell death is a phenomenon of widespread biological importance (27) that is characterized by structural changes in the nucleus and a pattern of chromatin fragmentation indicative of endogenous endonuclease activation. Recent interest has focused on its role in corticosteroid-treated thymocytes $(24,29)$ and its importance as a suicide mechanism in the cellular targets of cytotoxic lymphocytes $(28,31)$. In these examples the triggering event is clear, although the intracellular mechanisms leading to endonuclease activation are poorly understood. In other examples, such as the programmed cell death that occurs during embryological remodeling (33), the trigger factors are completely obscure. However, embryological remodeling and thymus involution (27) provide analogies that may be important to our understanding of neutrophil disposal in inflammation, because programmed cell death in these situations leads to the removal of unwanted cells without apparently causing tissue injury or initiating an inflammatory response (27). Because this process leads to macrophage recognition of the aged neutrophil at a stage when the cell membrane is structurally and functionally intact, and large amounts of granule enzymes have not necessarily been disgorged, it may represent a mechanism for the removal of effete neutrophils that normally serves to limit the degree of tissue injury in inflammation.

In the present study improved methods of neutrophil isolation and culture were used, so that during $24 \mathrm{~h}$ in vitro there was negligible loss of cells and $>98 \%$ retained the ability to exclude the vital dye trypan blue. A progressive, time-related increase in the degree of macrophage recognition of such cells over $24 \mathrm{~h}$ was confirmed. Over this period, and in parallel with the increase in macrophage recognition, there was a progressive increase in the proportion of neutrophils that displayed morphological features of programmed cell death. This process was originally reported in corticosteroid-treated thymocytes $(24,29)$ and has since been described in a variety of cells and tissues where cell senescence or death occurs in a tightly regulated or programmed fashion $(27,28,31)$. Cells undergoing programmed cell death display a number of characteristic morphological features, including nuclear chromatin condensation or pyknosis on light microscopy and nucleolar prominence, chromatin aggregation, and cytoplasmic vacuolation on electron microscopy, while the cell membrane and organelles remain intact (27). Together with these structural changes there is evidence of endogenous endonuclease activation, indicated by the characteristic pattern of internucleosomal chromatin fragmentation $(24,25,29-31)$. Neutrophils aging in culture showed all these features, and these observations represent the first description of programmed cell death in a cell of the myeloid series.

The parallel increases in the proportion of neutrophils exhibiting features of apoptosis and the degree of macrophage recognition of aged neutrophils, together with a close correlation between the proportion of apoptotic cells in neutrophil populations of various ages and macrophage recognition, suggested a close link between the two processes. In other cells that undergo programmed cell death there is evidence that the process results in the intact cell becoming avidly engulfed by phagocytes $(25,27,32)$. It was, therefore, pertinent to determine whether programmed cell death in the neutrophil was directly related to recognition of the cell by macrophages. Our in vitro experiments suggest that the uptake and degradation processes are so rapid as to render it difficult to make confident judgements of the morphology of the majority of ingested neutrophils (19). Thus, the relationships between neutrophil apoptosis and phagocytosis by macrophages could not be defined by the comparatively simple expedient of morphological examination of macrophages after interaction. Instead, a direct relationship was demonstrated by separating aged neutrophil populations by counterflow centrifugation into fractions with varying proportions of apoptotic cells and confirming that the apoptotic subpopulation was responsible for macrophage recognition. Programmed cell death in the aging neutro- 


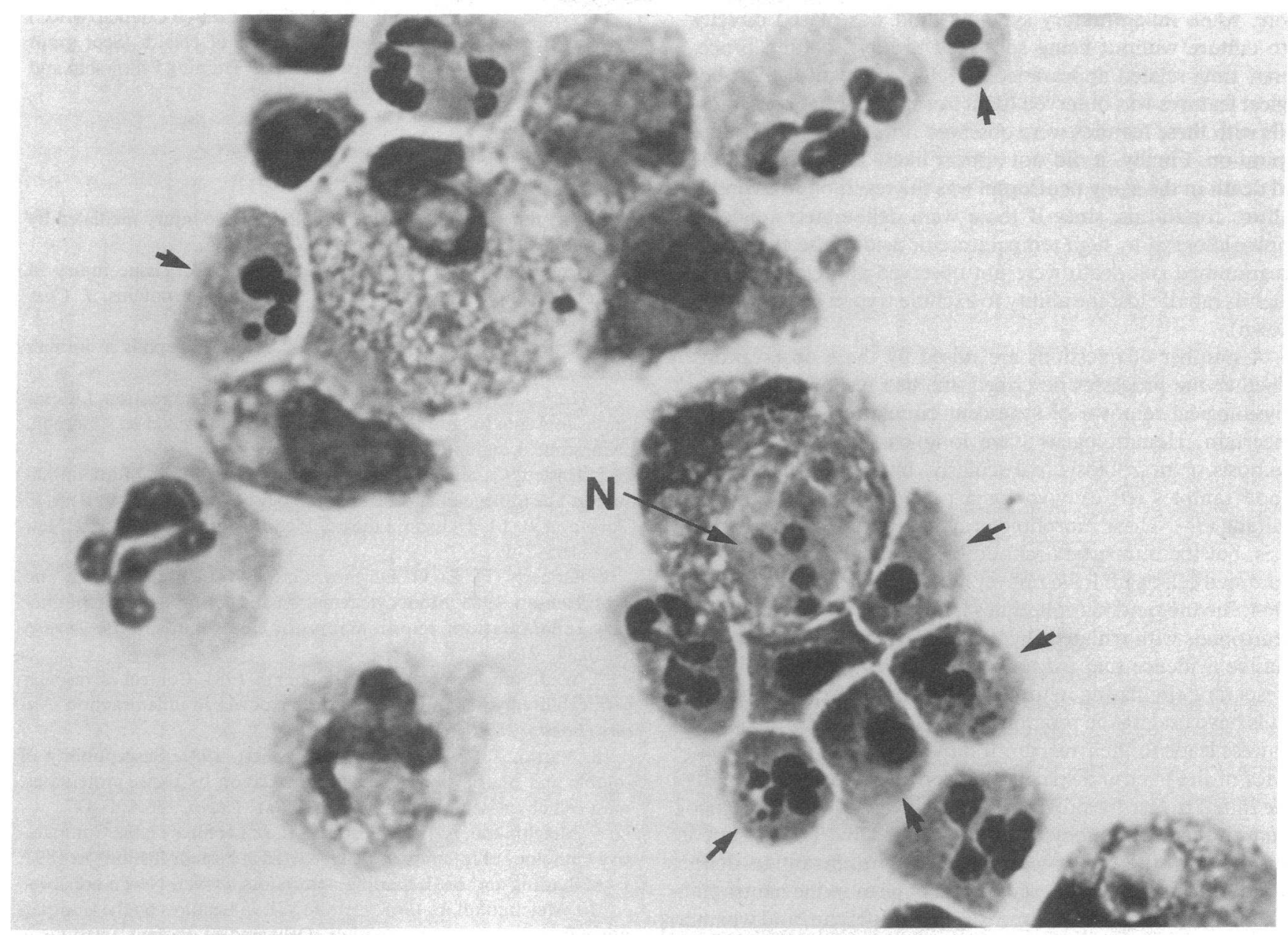

Figure 8. Light microscopy $(\times 1,000)$ of inflammatory cells freshly isolated from synovial fluid. Some neutrophils have morphological changes typical of apoptosis (arrows) and many macrophages appear to have ingested intact neutrophils. Note condensed nuclei of ingested neutrophils $(N)$.

phil, by leading to recognition by macrophages, therefore represents a mechanism accounting for macrophage phagocytosis of neutrophils in vitro (19).

It was considered important to establish whether age-related programmed cell death occurred in populations of neutrophils derived from inflamed sites and whether it might provide a mechanism for neutrophil disposal by macrophages in vivo. Our data indicate that the same processes account for instances of neutrophil ingestion by macrophages in vivo and offer new insights into the clinically described phenomenon of the Reiter's cell. First, populations of neutrophils that have migrated to inflamed sites in vivo underwent progressive morphological and biochemical changes typical of programmed cell death when isolated and cultured in vitro. Indeed, neutrophils with morphology typical of apoptosis were seen in freshly aspirated inflammatory synovial fluid. Second, inflammatory neutrophils undergoing apoptosis in vitro were recognized and ingested by heterologous monocyte-derived macrophages; nonapoptotic inflammatory neutrophils were recognized to a much smaller degree, if at all. Third, in a single patient with bilateral arthritis it was possible to compare the recognition of freshly isolated, aged, nonapoptotic and apoptotic neutrophils by freshly isolated inflammatory macrophages, all cells being derived from the same organ (knee joint) and patient, and to provide evidence that the apoptotic cells were preferentially recognized by autologous macrophages. Finally, the cytological appearances of the Reiter's cell in our own and other studies are consistent with macrophages that have recently taken up apoptotic neutrophils.

The studies in vitro suggest that neutrophil recognition, uptake, and degradation processes are rapid, as compared with the comparatively slow rate of development of neutrophil apoptosis. This seems likely to explain why relatively few neutrophils removed from the inflamed site were seen to exhibit features of apoptosis, i.e., the cells that have undergone this process have already been engulfed and degraded. The difficulty of assessing the dynamics of a cell disposal process from histological examination at one time point is well illustrated by studies of tissue involution and resorption, where cells in large areas of tissue undergo programmed death but relatively few phagocytes contain readily recognizable apoptotic cells at any one time $(27,33)$.

That the changes in the neutrophil population represent a physiological intrinsic aging process is suggested by the gradual increase in the proportion of cells showing these changes in vitro over $24 \mathrm{~h}$. The neutrophils do not appear to age in phase, suggesting that the phenomenon is not the result of their sudden isolation and exposure to ex vivo conditions. Further- 
more, when inflammatory synovial fluid was placed directly into culture without being subjected to any isolation procedures, time-related appearance of cells with typical morphological features was observed (data not shown), and occasional cells with these features were observed immediately after fluid aspiration. Finally, it did not appear likely that programmed cell death in the aging neutrophil was the result of unfavorable culture conditions, since if these were deliberately rendered unphysiological by high temperature or acidity the changes of programmed cell death were not observed and cultured neutrophils rapidly lost the ability to exclude trypan blue (data not shown).

A number of questions are raised by these observations. Whether the processes described are also responsible for the physiological removal of senescent circulating neutrophils is uncertain. Hematologists have long recognized neutrophil pyknosis or necrobiosis, particularly, but not exclusively, in blood samples left ex vivo for a period before fixation and staining (34). These morphological features are those of apoptosis, but the ultrastructural and biochemical changes of programmed cell death have not yet been sought. Furthermore, in 1964 Fliedner and his colleagues labeled human bone marrow neutrophils with tritiated thymidine in vivo and provided persuasive evidence that pyknosis was a senescence phase of the lifespan of circulating neutrophils (35). Whether such neutrophils have undergone programmed cell death and whether this process leads to their recognition by the mononuclear phagocytes of the liver and spleen is under investigation. Secondly, the initial trigger for programmed cell death is clear in corticosteroid-treated thymocytes or cells killed by $T$ cells, but is obscure in other cell types. It will be important to define whether the process is an innate mechanism in the neutrophil, whether it is triggered at some stage of its lifespan, and whether its rate can be influenced by environmental conditions. Finally, the relationship between the morphological changes of programmed cell death and the surface changes leading to recognition of the cell as nonself remains obscure. Even in the steroid-treated thymocyte, which represents the best-characterized example of programmed cell death, the surface determinants responsible for macrophage recognition are poorly defined, although there is some evidence for a sugar-lectin recognition mechanism $(32,36)$.

In conclusion, we have shown that human neutrophils derived from peripheral blood or acutely inflamed joints and aged in culture undergo morphological and chromatin fragmentation changes of programmed cell death. This process leads to the recognition of aged neutrophils by macrophages at a stage when their cell membrane appears structurally and functionally intact. Programmed cell death is important in tissue kinetics and, in these situations, leads to the removal of unwanted cells without inducing inflammation or tissue injury. Our observations may therefore represent a neutrophil removal mechanism that is important in the resolution of inflammation and the limitation of tissue injury in acute inflammation.

\section{Acknowledgments}

The authors wish to thank Alison Lee, Sarah Hall, Irene Evans, and Scott Young for expert technical assistance, and Mrs. Ann Power and Ms. Brenda Johnson for their excellent secretarial work.
This work was supported by the Medical Research Council (MRC) of Great Britain and the National Institutes of Health (Scor grant HL-27353). Dr. Savill is in receipt of a MRC Training Fellowship and Dr. Haslett is a MRC Senior Clinical Fellow.

\section{References}

1. Cochrane, C. G. 1968. Immunologic tissue injury mediated by neutrophilic leukocytes. Adv. Immunol. 9:97-165.

2. Henson, P. M., and R. B. Johnston. 1987. Tissue injury in inflammation. Oxidants, proteinases, and cationic proteins. J. Clin. Invest. 79:669-674.

3. Malech, H. D., and J. I. Gallin. 1988. Neutrophils in human diseases. $N$. Engl. J. Med. 37:687-694.

4. Hurley, J. V. 1983. Termination of acute inflammation. I. Resolution. In Acute Inflammation. J. V. Hurley, editor. 2nd ed. Churchill Livingstone, London. 109-117.

5. Haslett, C., and P. M. Henson. 1988. Resolution of inflammation. In The Molecular and Cellular Biology of Wound Repair. R. A. F. Clark and P. M. Henson, editors. Plenum Publishing Corp., New York. 185-211.

6. Doherty, D. E., G. Downey, G. S. Worthen, C. Haslett, and P. M. Henson. 1988. Monocyte retention and accumulation in pulmonary inflammation: requirements for neutrophils. Lab. Invest. 59(2):200-213

7. Wedmore, C. V., and T. J. Williams. 1981. Control of vascular permeability by polymorphonuclear leukocytes in inflammation. $\mathrm{Na}$ ture (Lond.). 289:646-650.

8. Vartio, T., H. Seppa, and A. Vaheri. 1981. Susceptibility of soluble and matrix fibronectin to degradation by tissue proteinases, mast cell chymase and cathepsin G. J. Biol. Chem. 256:471-477.

9. Metchnikoff, E. 1968. Lecture VII. In Lectures on the Comparative Pathology of Inflammation. Delivered at Pasteur Institute in 1891. F. A. Starling and E. H. Starling, translators. Dover, New York. 106.

10. Metchnikoff, E. 1968. Lecture VII. In Lectures on the Comparative Pathology of Inflammation. Delivered at Pasteur Institute in 1891. F. A. Starling and E. H. Starling, translators. Dover, New York. 153.

11. Brewer, D. B. 1964. Electron-microscope phagocytosis of neutrophil polymorphonuclear leukocytes by macrophages. J. Pathol. 88:307-310.

12. Nichols, B. A., and D. F. Bainton. 1975. Ultrastructure and cytochemistry of mononuclear pahgocytes. In Mononuclear Phagocytes in Immunity, Infection and Pathology. R. van Furth, editor. Blackwell, London. 39.

13. Sanui, H., S.-i. Yoshida, K. Nomoto, R. Ohhara, and Y. Adachi. 1982. Peritoneal macrophages which phagocytose autologous polymorphonuclear leucocytes in guinea-pigs. I. Induction by irritants and microorganisms and inhibition by colchicine. Br. J. Exp. Pathol. 63:278-285.

14. Chapes, S. K., and S. Haskill. 1983. Evidence for granulocytemediated macrophage activation after $C$. parvum immunization. Cell. Immunol. 75:367-377.

15. Kadri, A., M. Moinuddin, and N. K. M. De Leeuw. 1975. Phagocytosis of blood cells by splenic macrophages in thrombotic thrombocytopaenic purpura. Ann. Intern. Med. 82:799-802.

16. Parmely, R. T., W. M. Christ, A. H. Ragab, L. A. Boxer, A. Malluh, and H. Findley. 1981. Phagocytosis of neutrophils by marrow macrophages in childhood benign neutropaenia. J. Pediatr. 98:207211.

17. Pekin, T., T. I. Malinin, and N. J. Zwaifler. 1967. Unusual synovial fluid findings in Reiter's syndrome. Ann. Intern. Med. 66:677-684.

18. Spriggs, R. S., M. M. Boddington, and A. G. Mowat. 1978. Joint fluid cytology in Reiter's disease. Ann. Rheum. Dis. 37:557-560.

19. Newman, S. L., J. E. Henson, and P. M. Henson. 1982. Phagocytosis of senescent neutrophils by human monocyte-derived macro- 
phages and rabbit inflammatory macrophages. J. Exp. Med. 156:430442.

20. Haslett, C., L. A. Guthrie, M. M. Kopaniak, R. B. Johnston, and P. M. Henson. 1985. Modulation of multiple neutrophil functions by preparative methods or trace concentrations of bacterial lipopolysaccharide. Am. J. Pathol. 119:101-110.

21. Henson, P. M., B. Zanolari, N. A. Schwartzman, and S. R. Hong. 1978. Intracellular control of human neutrophil secretion. I. C5a-induced stimulus-specific desensitisation and the effects of cytochalasin B. J. Immunol. 121:851-855.

22. Hacbarth, E., and A. Kajdacsy-Balla. 1986. Low density neutrophils in patients with systemic lupus erythematosis, rheumatoid arthritis, and acute rheumatic fever. Arthritis Rheum. 29:1334-1341.

23. Musson, R. A. 1983. Human serum induces maturation of human monocytes in vitro. Am. J. Pathol. 111:331-340.

24. Wyllie, A. H. 1980. Glucocorticoid-induced thymocyte apoptosis is associated with endogenous endonuclease activation. Nature (Lond.). 284:555-556.

25. Wyllie, A. H., and R. E. Morris. 1985. Hormone induced cell death: purification and properties of thymocytes undergoing apoptosis after glucocorticoid treatment. Am. J. Pathol. 109:78-87.

26. Haslett, C., G. S. Worthen, P. C. Giclas, D. C. Morrison, J. E. Henson, and P. M. Henson. 1987. The pulmonary vascular sequestration of neutrophils in endotoxemia is initiated by an effect of endotoxin on the neutrophil in the rabbit. Am. Rev. Respir. Dis. 136:9-18.

27. Wyllie, A. H., J. F. R. Kerr, and A. R. Currie. 1980. Cell death: the significance of apoptosis. Int. Rev. Cytol. 68:251-306.
28. Russell, J. H. 1983. Internal disintegration model of cytotoxin lymphocyte-induced target damage. Immunol. Rev. 72:97-118.

29. Cohen, J. J., and R. C. Duke. 1984. Glucocorticoid activation of a calcium dependent endonuclease in thymic nuclei leads to cell death. J. Immunol. 132:38-42.

30. Wyllie, A. H., R. G. Morris, A. L. Smith, and D. Dunlop. 1984. Chromatin cleavage in apoptosis: association with condensed chromatin morphology and dependence on macromolecular synthesis. $J$. Pathol. 142:67-77.

31. Ucker, D. S. 1987. Cytotoxic lymphocytes and glucocorticoids activate an endogenous suicide process in target cells. Nature (Lond.). 327:62-64.

32. Duvall, E., A. H. Wyllie, and R. E. Morris. 1985. Macrophage recognition of cells undergoing programmed cell death (apoptosis). Immunology. 56:351-358.

33. Ballard, K. J., and S. J. Holt. 1968. Cytological and cytochemical studies on cell death and digestion in the foetal rat foot: the role of macrophages and hydrolytic enzymes. J. Cell Sci. 3:245-257.

34. Undritz, E. 1973. Sandoz Atlas of Haematology. E. Undritz, editor. 2nd ed. Sandoz Ltd., Basel, Switzerland. Sections 137, 412, and 416.

35. Fliedner, T. M., E. P. Cronkite, and J. S. Robertson. 1964. Granulocytopoiesis. I. Senescence and random loss of neutrophilic granulocytes in human beings. Blood. 24:402-414.

36. Morris, R. G., A. D. Hargreaves, E. Duvall, and A. M. Wyllie. 1984. Hormone induced cell death 2 . Surface changes in thymocytes undergoing apoptosis. Am. J. Pathol. 115:426-436. 